\title{
Preliminary Characterization, Antioxidant and Antiproliferative Properties of Polysaccharide from Caulerpa taxifolia
}

\author{
Ariane Marie Bayro*, Joanne Katherine Manlusoc, Renaliza Alonte, Catherine Caniel, \\ Patrick Conde, Carlo Embralino \\ College of Pharmacy, Adamson University, 900 San Marcelino Ermita, Manila, Philippines
}

\begin{abstract}
Macroalgae are abundant sources of bioactive polysaccharides and prospective candidates for effective and non-toxic substances. This study aims to preliminary characterize and determine the in vitro antioxidant activity and cancer cell growth inhibitory activity against human lung adenocarcinoma cell (A549) of the polysaccharide from an invasive green alga, Caulerpa taxifolia. Crude polysaccharide (CP) was extracted from the dried algal sample of $C$. taxifolia by hot water extraction followed by absolute ethanol precipitation. $\mathrm{CP}$ was subjected to preliminary chemical characterization, including protein, carbohydrate, and sulfate content analysis by Kjeldahl titrimetry, acid hydrolysis, gravimetry, and ashing-acid water digestion ion chromatography, respectively. Functional groups present in the CP were determined by Fourier transform infrared spectroscopy (FT-IR). Antioxidant activity was evaluated by 1, 1-diphenyl-2-picrylhydrazyl radical (DPPH) free radical scavenging activity assay. The cancer cell growth inhibitory activity against A549 cells was evaluated by MTT assay. Chemical composition of the CP shows $68.4 \%(\mathrm{w} / \mathrm{w})$ carbohydrate, 9.4\% $(\mathrm{w} / \mathrm{w})$ protein, and $0.74 \%(\mathrm{w} / \mathrm{w})$ sulfate. FT-IR showed the presence of $-\mathrm{OH}$ group, $\mathrm{C}-\mathrm{H}$ stretch groups, $\mathrm{C}=\mathrm{O}$ groups, and $\mathrm{C}-\mathrm{O}$ groups and suggested a pyranose configuration of the sugar structure. MTT assay showed the highest inhibition at $25 \mu \mathrm{g} / \mathrm{mL}$ concentration with $35.50 \% \pm 1.66$ SEM with a relative IC50 of $45.44 \mu \mathrm{g} / \mathrm{mL}$. However, the DPPH assay did not exhibit remarkable free radical scavenging capacity than other studies of polysaccharides with only $18.33 \%$ at $1 \mathrm{mg} / \mathrm{mL}$. This exploratory study paves the way to explore the mechanism of action of polysaccharides from marine algae as a possible anticancer treatment.
\end{abstract}

ARTICLE HISTORY

Received: September 2020 Revised: April 2021 Accepted : April 2021
Keywords: antiproliferative; antioxidant; Caulerpa taxifolia; polysaccharide

\section{INTRODUCTION}

Pollutants are considered as a generator of free radicals that attack the human body's macromolecules by producing oxygen-containing free radicals leading to homeostatic disruption and cellular destruction that may cause disease states and eventually leading to cancer (Lobo, 2010). Lung cancer is the top cause of cancerrelated deaths among men and women, outranked by breast and cervical cancer. Due to the increasing death rate because of lung cancer, advances in diagnostic techniques and search for new chemotherapy drugs have been made. Platinum-based chemotherapeutics such as cisplatin remains the most successful agent in treating lung cancer and is usually co-administered with other chemotherapeutics (Lee et al., 2013). Another anticancer agent, Doxorubicin, with broad-spectrum activity to treat different kinds of cancer, including lung cancer, may cause significant adverse drug reactions. Furthermore, chemotherapeutic drugs may cause cardiotoxicity (Rivankar, 2014). The explorational study of natural resources might be essential in finding alternatives for cancer treatments.
Marine alga, commonly known as seaweeds, are widely recognized as a major food source, especially for Asians ( $\mathrm{Li}$ et al., 2017). These seaweeds contain minerals, vitamins, antioxidants, soluble dietary fibers, phytochemicals, and other polyunsaturated fatty acids. They have a lesser caloric value that made them widely known as a source of consumables. Having an array of benefits from a marine alga, researchers became interested in what components comprised one of these activities. Previous studies reported that bioactive isolated from the seaweeds showed promising pharmacological activities, such as antioxidant, anti-inflammatory, antiproliferative, and anticoagulant activities (Yende, 2014).

Caulerpa taxifolia is a green alga which is commonly found as a decorative plant in seawater aquaria. The ecological harm of C. taxifolia is that it colonizes a large area of the sea, specifically on the bottom of a water body. It is listed as one of only two marine species that belong to the worst invaders in the world (Schofield \& Brown, 2016). This study was carried out to characterized and determined the in-vitro antioxidant activity and cancer cell growth inhibitory activity against human lung 
carcinoma A549 cells of the polysaccharide from an invasive green alga, $C$. taxifolia.

\section{METHOD}

\section{Standard, Reagents, and Chemicals}

All standards, reagents, and chemicals used in this study are analytical grades provided by the Pharmacy Laboratory of Adamson University. DPPH (2,2-diphenyl-1-picrylhydrazyl) assay kit was purchased from Sigma-Aldrich. MTT (3-(4,5dimethylthiazol-2yl)-2,5-diphenyl) tetrazolium bromide assay was done at University of the Philippines Diliman-Mammalian Cell Culture Laboratory (MCCL).

\section{Algal Sample Collection and Identification \\ Fifty (50) kilograms of fresh thalli of C. taxifolia was collected in November 2018 at the coastline of Dancalan, Bulusan, Province of Sorsogon, Bicol, Philippines, with a permit from the Bureau of Fisheries and Aquatic Resources (BFAR) Region V. Fresh algal samples were cleaned manually with seawater, tap water, and deionized water to free the seaweeds from any foreign materials.}

The fresh sample and herbarium specimen was sent to the Marine Science Institute of College of Science from the University of the Philippines Diliman for identification and authentication and was given accession number MSI27995.

\section{Plant Extraction}

Fresh algal samples were thoroughly cleaned from any debris, were air-dried in the shade, milled, and sieved with mesh no. 100 to attain a uniform particle size. The crude polysaccharide extraction was performed according to the method of Qi et al. (2012). A total of $700 \mathrm{~g}$ of milled algal powder was suspended in $7 \mathrm{~L}$ volume of deionized water, homogenized, and refluxed at $100^{\circ} \mathrm{C}$ for 7 hours, and the mixture was centrifuged at $3600 \mathrm{rpm}$ for 30 mins. The residue was collected and subjected to the second extraction using the same procedure. Ethanol (95\%) was added into the collected supernatant and was refrigerated at $8^{\circ} \mathrm{C}$ overnight. The suspension was centrifuged at 3600 rpm for $30 \mathrm{mins}$, and the precipitate was collected. The crude polysaccharide (CP) was triturated into its fine powder form. The yield was calculated based on the weight of dried biomass obtained after treating the milled sample with $95 \% \mathrm{EtOH}$ using the formula:

$\%$ yield $=\frac{\text { weight of the precipitated polysaccharide of C.taxifolia }}{\text { weight of dried C.taxifolia }} \times 100$

\section{Characterization of $\mathbf{C P}$}

The sulfate content of $\mathrm{CP}$ was determined by ashing acidwater digestion and ion chromatography. The amount of sulfate was computed from a standard curve prepared from the peak area reading of standard sulfates. The protein content of the $\mathrm{CP}$ of $C$. taxifolia was obtained by Kjeldahl Titrimetry method. The carbohydrate content of the CP was calculated using the obtained amount of protein, fat, moisture, and ash content.

\section{Functional Group Identification of CP using (FT-IR)}

CP was subjected to FT-IR spectroscopy using Attenuated Total Reflectance (ATR) and measured in the frequency range of 4000-550 $\mathrm{cm}^{-1}$. FT-IR spectrum was performed on a Lambda 365 UV Vis Spectrum 2 Fourier Transform Infrared Spectroscopy, PerkinElmer.

\section{DPPH Assay}

A stock solution of $0.1 \mathrm{mM}$ of DPPH was prepared by diluting DPPH in pure methanol. Sample solution consisted of diluting CP into deionized water. The same was performed using ascorbic acid as the standard. The sample solution preparation was serially diluted in different concentrations $(1000,500,250$, and $125 \mu \mathrm{g} /$ $\mathrm{mL}$ ), and this procedure was also done for the standard. In a 96 microwell plate, $30 \mu \mathrm{L}$ of sample solution +270 $\mu \mathrm{L}$ of DPPH stock solution was micro pipetted in each well. The mixture was incubated in the dark for 30 mins, and the absorbance was measured at $518 \mathrm{~nm}$. The test was performed in triplicates. Percent scavenging (\% SC) was computed based on the formula. Where $\mathrm{A}_{\mathrm{o}}$ is the absorbance of the control, and $\mathrm{A}_{1}$ is the absorbance of the sample.

$$
\% \mathrm{SC}=\left(\left(\mathrm{A}_{\mathrm{o}}-\mathrm{A}_{1}\right) / \mathrm{A}_{\mathrm{o}}\right) \times 100
$$

\section{MTT Assay}

The antiproliferative activity of $\mathrm{CP}$ against human lung carcinoma (A549) was determined by MTT assay following the method of Mosmann (1983). Cell proliferation assay was measured by seeding $1 \times 10^{4}$ cells in 96 microwell plates in normal cell growth media, Gibco Dulbecco's Modified Eagle Medium (DMEM). The culture plate was incubated with the MTT solution for 24 hours with a temperature of $37^{\circ} \mathrm{C}$ with a humidified atmosphere of $5 \% \mathrm{CO}_{2}$. After incubation, a water-insoluble formazan dye is formed, $10 \mathrm{~mL}$ of MTT reagent was added and incubated for 4 hours. MTT reagent was removed, and DMSO was added. The formazan dye is quantitated using a scanning multi-well spectrophotometer (ELISA reader) with an absorbance of $570 \mathrm{~nm}$. The absorbance that was measured directly correlates to the number of viable cells. The percent cell viability was computed based on the formula:

Cell Viability $\%=\frac{\text { Total viable cells }(\text { unstained })}{\text { total cells }(\text { stained and unstained })} \times 100$

\section{Statistical Analysis}

The DPPH assay was done in three trials and MTT assay was performed in duplicate of three trials. Data were presented as \pm standard error of means (SEM) of triplicates. 


\section{RESULT AND DISCUSSION}

\section{Extraction Yield and Physical Characteristics}

The dried crude polysaccharide (CP) obtained from 700 $\mathrm{g}$ of dried algal sample yielded $0.81 \%(5.621 \mathrm{~g})$. The obtained $\mathrm{CP}$ is a brown powder with a fishy odor.

\section{Sulfate Content Determination of CP}

The sulfate content, which is essential for the possible antioxidant activity of CP, was present with amounts of $0.74 \%(\mathrm{w} / \mathrm{w})$. Sulfate was determined by ashing acidwater digestion and ion chromatography and eluted a retention time of 12.969 minutes with an area of 238961 $\mathrm{mAu}$.

Sulfate content of the CP of C. taxifolia was relatively low compared to the study of Shao et al. (2014) that native polysaccharide fractions of $U$. fasciata (UFP) showed high scavenging activity ranging from 30.16-34.75\% at low concentrations of $0.1 \mathrm{mg} / \mathrm{ml}$. Several studies revealed that the sulfate content in polysaccharides is one of the main factors that contribute to its antioxidant activity. Likewise, the study of Wang et al. (2014) showed a high inhibitory effect of low molecular weight of $E$. linza (LEP) and high molecular weight of $E$. linza (HEP) with $85.6 \%$ and $82.1 \%$ at a concentration of 40 $\mathrm{mcg} / \mathrm{ml}$, respectively. LEP shows many free hydroxyl groups compared to HEP, which may lead to higher antioxidant activity. Therefore, it suggests that the antioxidant activity of different polysaccharides varies with their sulfate content.

\section{Protein Content Determination of $\mathbf{C P}$}

The CP from $C$ taxifolia contains $9.4 \%$ (w/w) protein. According to Angell et al. (2015), seaweed protein content varies between taxonomic groups, wherein green seaweed has the highest protein mean content. The study of Matanjun (2008) showed that green seaweed, C. lentillifera has the highest protein content of $10.41 \%$ among brown seaweed, S. polycystum and red seaweed, E. cottonii. In addition, the study of Giang et al. (2016) showed that $S$. microcystum has a significant protein content of $5.7 \pm 1.5$ and an antioxidant activity. In relation, the presence of phenolics and proteins enhanced the overall antioxidant activity (Sellimi et al., 2017).

\section{Carbohydrate Content Determination of CP}

The carbohydrate content was found to be $68.4 \% \mathrm{w} / \mathrm{w}$. It was calculated using the obtained amount of protein $(9.4 \% \mathrm{w} / \mathrm{w})$, fat $(5.3 \% \mathrm{w} / \mathrm{w})$, moisture $(10.8 \% \mathrm{w} / \mathrm{w})$, and ash content $(6.1 \% \mathrm{w} / \mathrm{w})$. Seaweeds are comprised primarily of polysaccharides which are made up of carbohydrate monomers. The high carbohydrate content in C. taxifolia was in agreement with the reported contents in most green algae, such as with the study of Mahendran (2013), where the extract yielded a carbohydrate content of $47.43 \%$ and showed a significant scavenging activity.

Functional Group Identification using (FT-IR) of CP The FT-IR spectra of $C$. taxifolia were compared with the FT-IR spectra of the standard, ulvan, from the study of Alves et al. (2018) (Figure 1 \& Figure 2). High IR absorption was observed at $3340 \mathrm{~cm}^{-1}$ in the sample, while on the standard, the band is at $3433 \mathrm{~cm}^{-1}$ which may be attributed to the stretching of primarily $-\mathrm{OH}$ group and may also be indicated as N-H group. Other absorption bands at $2923 \mathrm{~cm}^{-1}$ and $2939 \mathrm{~cm}^{-1}$ on the sample and standard, respectively, were associated with the stretching signals of $\mathrm{C}-\mathrm{H}$ groups. The stretching associated with the peak at $1645 \mathrm{~cm}^{-1}$ is suggestive of a $\mathrm{C}=\mathrm{O}$ assigned as aromatic conjugate. Absorption bands at $1235 \mathrm{~cm}^{-1}$ in the sample and between $1000 \mathrm{~cm}^{-1}$ and $1200 \mathrm{~cm}^{-1}$ in the standard may be attributed to the sugar ring and glycosidic bond $\mathrm{C}-\mathrm{O}$ stretching vibrations. The

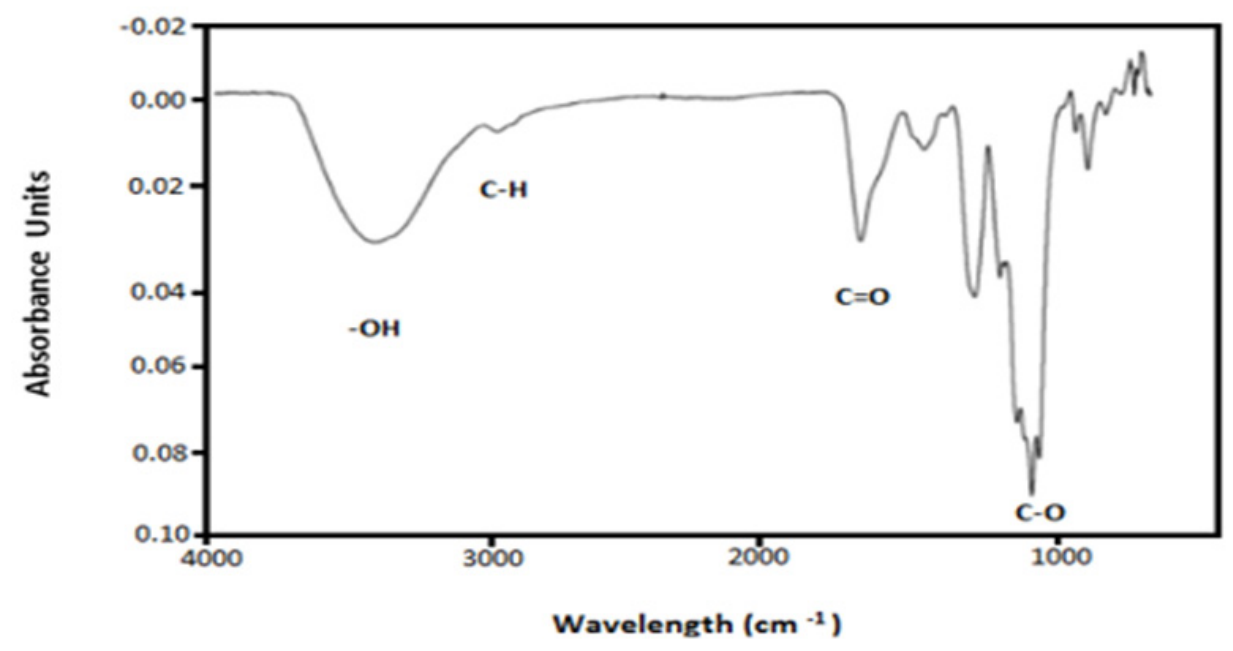

Figure 1. The FT-IR spectrum of standard Ulvan (Alves et al., 2018) 


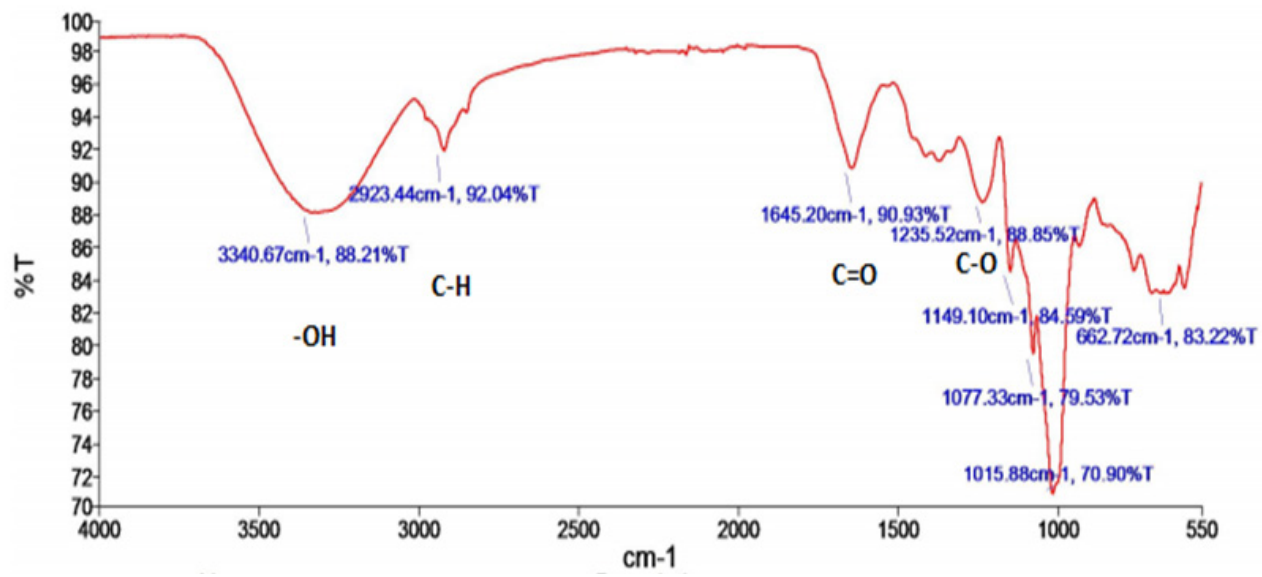

Figure 2. The FT-IR spectrum of the CP of $C$. taxifolia.

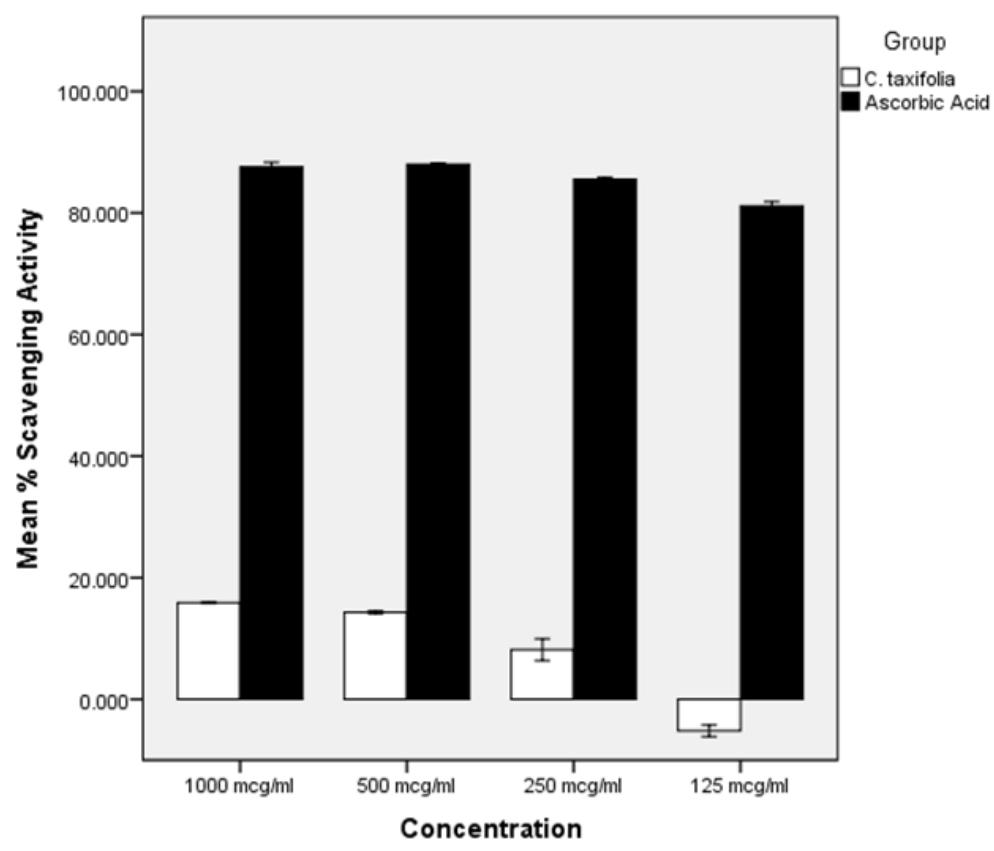

Error Bars: +/- $1 \mathrm{SE}$

Figure 3. Comparison between the percent scavenging from the computed absorbance reading of $\mathrm{CP}$ of $C$. taxifolia and Ascorbic Acid using DPPH (2,2-diphenyl-1-picrylhydrazyl) assay for antioxidant activity.

peaks at $1149 \mathrm{~cm}^{-1}, 1077 \mathrm{~cm}^{-1}$, and $1015 \mathrm{~cm}^{-1}$ in the sample and $1164 \mathrm{~cm}^{1}, 1085 \mathrm{~cm}^{-1}$, and $1034 \mathrm{~cm}^{-1}$ on the standard likely indicate the pyranose configuration of the sugar structure (Tabarsa et al., 2018).

Based on the detected functional groups in the sample, CP of C. taxifolia, similarities were observed with the standard ulvan, namely the pyranose and sugar structure. Thus, CP from C. taxifolia is a polysaccharide.
Free Radical Scavenging Activity of CP using DPPH Assay

DPPH is a compound that possesses a nitrogen-free radical and is readily destroyed by a free radical scavenger. This assay was used to test the ability of some compounds about their antioxidative activity working as the radical proton scavengers or hydrogen donors (Yangthong et al., 2009). 


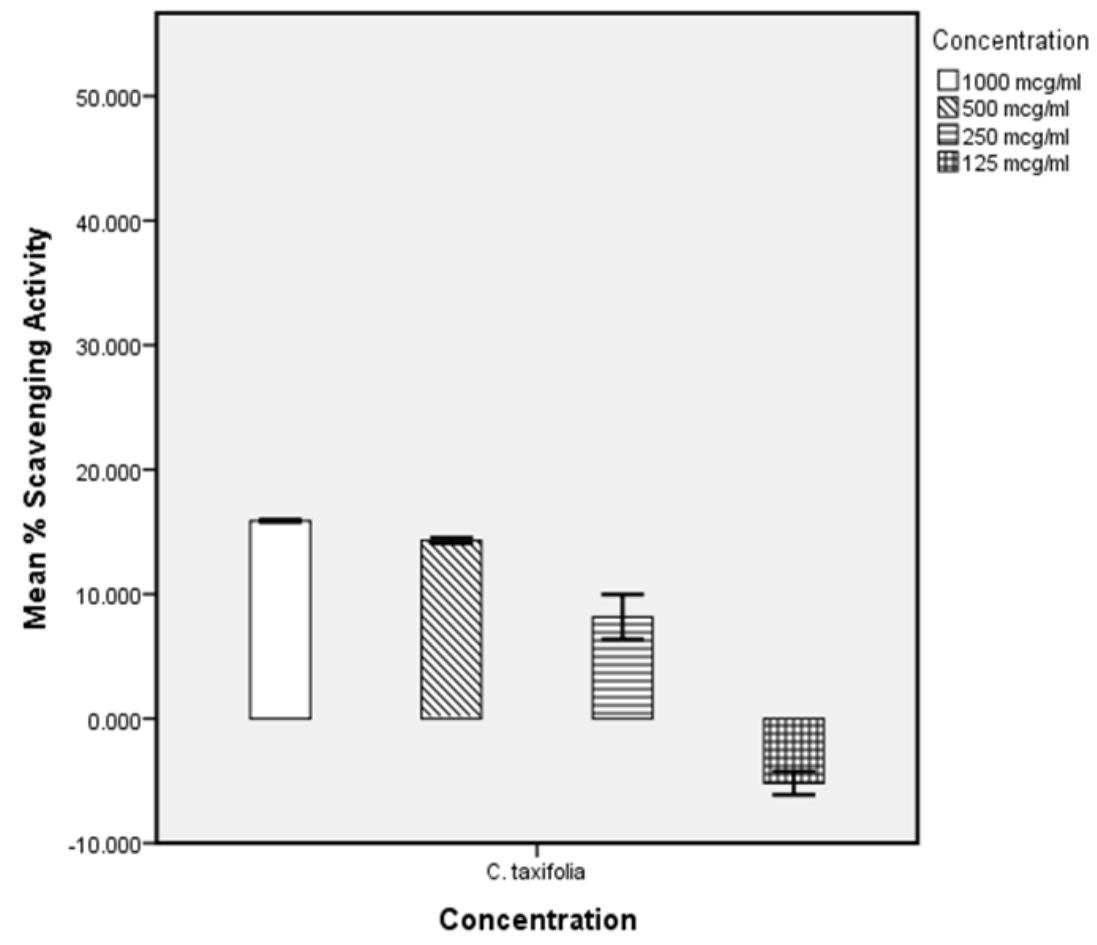

Error Bars: +/- 1 SE

Figure 4. Percent inhibition computed from the absorbance readings of $\mathrm{CP}$ from $C$. taxifolia, against human lung adenocarcinoma cells (A549) using MTT assay.

The scavenging property of the CP was expressed in percent scavenging (\%SC). The results of the DPPH assay are shown in Figure 3. The highest scavenging activity obtained from CP of C. taxifolia at $1000 \mu \mathrm{g} / \mathrm{mL}$ was $15.88 \%$. Thus, DPPH radical scavenging activity results from the crude CPs can be connected with the concentration-dependent means.

A study claimed that the potent scavenging effect of DPPH radicals could be linearly correlated with crude extracts rich in phenolic and sulfate contents. Thus, the slight free radical scavenging activity of $\mathrm{CP}$ may be attributed to the low sulfate content. Also, this finding can be supported with a report acknowledging that protein content can negatively contribute to the antioxidant activity of the crude $\mathrm{CP}$ for the presence of $\mathrm{NH}_{3}$ and $\mathrm{COOH}$ groups or amino groups that are found in the $\mathrm{CP}$, which can interact with the charge of $\mathrm{CP}$ forming a complex that could limit the efficiency of the scavenging property (Imjongjairak et al., 2016).

\section{Cytotoxicity Test using MTT Assay against Human Lung Adenocarcinoma (A549)}

The MTT (3-[4,5-dimethylthiazol-2-yl]-2,5diphenyl tetrazolium bromide) assay was based on the reduction of the dye formazan by live cells. MTT will be converted to a purple-colored formazan product if a viable cell contains active metabolism. When the cells die, they will lose the ability to turn MTT to formazan (Coussens et al., 2018).

The result showed the highest inhibition at $25 \mu \mathrm{g} / \mathrm{mL}$ with $35.50 \% \pm 1.66$ SEM (Figure 4) against A549 with a relative $\mathrm{IC}_{50}$ of $45.44 \mu \mathrm{g} / \mathrm{mL}$. The sample exhibited cytotoxic activity by inhibiting proliferation or growth, though it is not as potent as the reference standard, doxorubicin. The low amount of sulfate content may be accounted for this result. A study stated that an increase in sulfate content potentiates the cytotoxic effect of fucoidan, the active constituent present in marine algae responsible for exhibiting cytotoxic activity (Fedorov et al., 2013). Also, a study of Ghandehari et al. (2015), rationalize that presence of protein or peptide moiety in polysaccharide may be accountable for cytotoxic activity. The low cytotoxic activity of CP of $C$. taxifolia may also be attributed to the culture term of the A549 cell line because according to the European Collection of Authenticated Cell Cultures, it is recommended that if dealing with lung disease researches, the cell lines should be maintained in long term culture, around 20 days (Cooper, 2012).

\section{CONCLUSION}

Results obtained from this study suggested that $C$. taxifolia is an indicative source of possible polysaccharide 
content due to the presence of functional groups of presumably a pyranose ring structure. The antioxidant and antiproliferative properties of the crude extract in DPPH and MTT assay showed a little scavenging activity and a minor effect on cancer cell lines. Sulfate content has a significant impact on antioxidant activity. Based on our result of sulfate content characterization, a low amount of sulfate was present in the crude extract.

The DPPH and MTT assay results of CP from C. taxifolia may possess a different mechanism of cell death present from other polysaccharide studies. This preliminary study paves the way in exploring other mechanistic approaches on how polysaccharides from marine algae are utilized as a possible anticancer treatment.

\section{REFERENCES}

Alves, C., Silva, J., Pinteus, S., Gaspar, H., Alpoim, M. C., Botana, L. M., \& Pedrosa, R. (2018). From marine origin to therapeutics: the antitumor potential of marine algae-derived compounds. Frontiers in Pharmacology, 9, 777.

Angell, A., Mata, L., de Nys, R., \& Paul, N. (2015). The protein content of seaweeds: a universal nitrogento-protein conversion factor of five. Journal of Applied Phycology, 28(1), 511-524.

Cooper, J. (2012). Cell Line Profile A549.

Coussens, N. P., Sittampalam, G. S., Guha, R., Brimacombe, K., Grossman, A., Chung, T., Weidner, J. R., Riss, T., Trask, O. J., Auld, D., Dahlin, J. L., Devanaryan, V., Foley, T. L., McGee, J., Kahl, S. D., Kales, S. C., Arkin, M., Baell, J., Bejcek, B., GalEdd, N., ... Austin, C. P. (2018). Assay guidance manual: quantitative biology and pharmacology in preclinical drug discovery. Clinical and Translational Science, 11(5), 461-470.

Fedorov, S. N., Ermakova, S. P., Zvyagintseva, T. N., \& Stonik, V. A. (2013). Anticancer and cancer preventive properties of marine polysaccharides: some results and prospects. Marine Drugs, 11(12), 4876-4901.

Ghandehari, F., Behbahani, M., Pourazar, A., \& Noormohammadi, Z. (2015). In silico and in vitro studies of cytotoxic activity of different peptides derived from vesicular stomatitis virus $\mathrm{G}$ protein. Iranian Journal of Basic Medical Sciences, 18(1), 47-52.

Giang, T. T., Oanh, D. T. H., \& Giang. T. Q, P. v. H. T. (2016). Nghiên cứu ảnh hưởng của hỗn hợp polysaccharide chiết xuất từ rong mơ Sargassum microcystum lên tăng trưởng và tỉ lệ sống của cá tra
Pangasianodon hypophthalmus. Tap chi Khoa hoc Truòng Đai hoc Cân Tho, 47 (2016), 102-109

Imjongjairak, S., Ratanakhanokchai, K., Laohakunjit, N., Tachaapaikoon, C., Pason, P., \& Waeonukul, R. (2016). Biochemical characteristics and antioxidant activity of crude and purified sulfated polysaccharides from Gracilaria fisheri. Bioscience, Biotechnology, and Biochemistry, 80(3), 524-532.

Lee, J. C., Hou, M. F., Huang, H. W., Chang, F. R., Yeh, C. C., Tang, J. Y., \& Chang, H. W. (2013). Marine algal natural products with anti-oxidative, antiinflammatory, and anti-cancer properties. Cancer Cell International, 13(1), 55.

Li, J., Chi, Z., Yu, L., Jiang, F., \& Liu, C. (2017). Sulfated modification, characterization, and antioxidant and moisture absorption/retention activities of a soluble neutral polysaccharide from Enteromorpha prolifera. International Journal of Biological Macromolecules, 105(Pt 2), 1544-1553.

Lobo, V., Patil, A., Phatak, A., \& Chandra, N. (2010). Free radicals, antioxidants and functional foods: Impact on human health. Pharmacognosy Reviews, 4(8), 118126.

Mahendran, S. (2013). Purification and in vitro antioxidant activity of polysaccharide isolated from green seaweed Caulerpa racemosa. International Journal of Pharma and Bio Sciences, 1214-1227.

Matanjun, P., Mohamed, S., Mustapha, N., and \& Muhammad, K. (2008). Nutrient content of tropical edible seaweeds, Eucheuma cottonii, Caulerpa lentillifera and Sargassum polycystum. Journal of Applied Phycology, 21(1), 75-80.

Mosmann, T. (1983). Rapid colorimetric assay for cellular growth and survival: Application to proliferation and cytotoxicity assays. Journal of Immunological Methods, 65(1-2), 55-63.

Qi, X., Mao, W., Gao, Y., Chen, Y., Chen, Y., Zhao, C., Li, N., Wang, C., Yan, M., Lin, C., and \& Shan, J. (2012). Chemical characteristic of an anticoagulantactive sulfated polysaccharide from Enteromorpha clathrata. Carbohydrate Polymers, 90(4), 1804-1810.

Rivankar S. (2014). An overview of doxorubicin formulations in cancer therapy. Journal of Cancer Research and Therapeutics, 10(4), 853-858.

Schofield, P., \& Brown, M. (2016). Invasive species: ocean ecosystem case studies for earth systems and environmental sciences. Elsevier, 15.

E-ISSN 2477-0612 
Sellimi, S., Benslima, A., Barragan-Montero, V., Hajji, M., \& Nasri, M.(2017). Polyphenolic-protein-polysaccharide ternary conjugates from Cystoseira barbata Tunisian seaweed as potential biopreservatives: Chemical, antioxidant and antimicrobial properties. International Journal of Biological Macromolecules, 105(Pt 2), 13751383.

Shao, P., Pei, Y., Fang, Z., \& Sun, P. (2014). Effects of partial desulfation on antioxidant and inhibition of DLD cancer cell of Ulva fasciata polysaccharide. International Journal of Biological Macromolecules, 65, 307-313.

Tabarsa, M., You, S., Dabaghian, E. H., \& Surayot, U. (2018). Water-soluble polysaccharides from Ulva intestinalis: Molecular properties, structural elucidation and immunomodulatory activities. Journal of Food and Drug Analysis, 26(2), 599-608.
Wang, Z., Zhou, F. a, \&nd Quan, Y. (2014). Antioxidant and immunological activity in vitro of polysaccharides from Phellinus nigricans mycelia. International Journal of Biological Macromolecules, 64, 139-143.

Yangthong, M., Hutadilok-Towatana, N., \& Phromkunthong, W. (2009). Antioxidant activities of four edible seaweeds from the southern coast of Thailand. Plant Foods for Human Nutrition (Dordrecht, Netherlands), 64(3), 218-223.

Yende, S. R., Harle, U. N., \& Chaugule, B. B. (2014). Therapeutic potential and health benefits of Sargassum species. Pharmacognosy Reviews, 8(15), 1-7. 